\title{
Internalisasi Nilai-Nilai Luhur Pancasila dalam Mata Kuliah Pendidikan Pancasila di Perguruan Tinggi
}

\author{
Warsito \\ warsitosuranata79@gmail.com
}

\begin{abstract}
Abstrak
Kata kunci: Internalisasi, Nilai-nilai Luhur Pancasila, Mata kuliah pendidikan Pancasila, Perguruan Tinggi.

Pendidikan Pancasila mengalami pasang surut dalam pengimplementasiannya dalam berbagai aspek kehidupan. Dari sisi historis pembudayaan/pewarisan nilai-nilai Pancasila tersebut secara konsisten dilakukan sejak awal kemerdekaan sampai dengan sekarang. Bentuk dan intensitasnya berbeda, ini dapat dilihat pada masa awal kemerdekaan, pembudayaan nilai-nilai pancasila dilakukan dalam bentuk pidato-pidato-pidato para tokoh bangsa dalam rapat akbar yang disiarkan melalui radio dan surat kabar. Pada tanggal 1 Juli 1947, diterbitkan sebuah buku tentang Pidato Bung Karno mengenai lahirnya Pancasila. Perubahan yang drastis dalam pembudayaan Pendidikan Pancasila adalah setelah dekrit presiden 5 juli 1959. Pada tahun 1960, diterbitkan buku oleh Departemen Pendidikan dan Kebudayaan dengan judul Manusia dan Masyarakat Baru Indonesia. Buku tersebut bertujuan membentuk manusia Indonesia baru yang patriotik melalui Pendidikan.
\end{abstract}

Sejak lahirnya Ketetapan MPR RI, Nomor II/MPR.1978, tentang Pedoman Penghayatan dan Pengamalan Pancasila (P4) atau Ekaprasetia Pancakarsa, P4 tersebut kemudian menjadi salah satu sumber pokok materi Pendidikan Pancasila. Selain itu diperkuat lagi dengan TAP MPR RI Nomor II/MPR/1988 tentang GBHN yang mencantumkan bahwa Pendidikan Pancasila termasuk Pendidikan Pedoman Penghayatan dan Pengamalan Pancasila. Dalam rangka menyempurnakan Perkuliahan Pendidikan Pancasila yang digolongkan dalam mata kuliah dasar umum di perguruan tinggi, Dirjen Dikti menerbitkan SK Nomor 25/DIKTI/KEP/1985 tentang penyempurnaan Kurikulum Inti Mata Kuliah Dasar Umum (MKDU).

Ditetapkannya Undang-Undang Republik Indonesia Nomor 20 Tahun 2003 tentang sistem pendidikan nasional kembali mengurangi langkah pembudayaan Pancasila melalui pendidikan. Dalam undang-undang tersebut pendidikan pancasila tidak disebut sebagai mata kuliah wajib diperguruan tinggi sehingga beberapa universitas menggabungkan dalam materi Pendidikan Kewarganegaraan. Penguatan keberadaan mata kuliah Pancasila diperguruan tinggi ditegaskan dalam Pasal 35 jo Pasal 2 Undang-Undang Republik Indonesia Nomor 12 Tahun 2012 tentang Pendidikan Tinggi yang menetapkan ketentuan bahwa mata kuliah Pendidikan Pancasila wajib dimuat dalam kurikulum perguruan tinggi. Dalam rangka mengintensifkan kembali pembudayaan nila-nilai Pancasila kepada generasi penerus bangsa melalui pendidikan tinggi, dilakukan langkah-langkah antara lain melalui seminar-seminar tentang pentingnya pembudayaan Pancasila melalui pendidikan. 


\section{A. PENDAHULUAN}

\section{Tantangan Pendidikan Pancasila}

Dalam menentukan bentuk dan format agar mata kuliah Pendidikan Pancasila dapat diselenggarakan di berbagai program studi dengan menarik dan efektif terdapat berbagai tantangan. Tantangan ini dapat berasal dari internal perguruan tinggi, misalnya faktor ketersediaan sumber daya, dan spesialisasi program studi yang makin tajam (yang menyebabkan kekurangtertarikan sebagian mahasiswa terhadap Pendidikan Pancasila). Tantangan yang bersifat eksternal, antara lain adalah krisis keteladan dari para elite politik dan maraknya gaya hidup hedonistik di dalam masyarakat. Untuk mengetahui lebih dalam mengenai dinamika dan tantangan Pendidikan Pancasila pada era globalisasi, perlu menganalisis penggalan-penggalan pidato kebangsaan yang sudah pernah dilakukan oleh para tokoh bangasa (founding father).

Dalam Pasal 35 ayat (3) Undang-Undang Republik Indonesia Nomor 12 tahun 2012 tentang Pendidikan Tinggi, yang dimaksud dengan mata Kuliah Pendidikan Pancasila adalah pendidikan untuk memberikan pemahaman dan penghayatan kepada mahasiswa mengenai ideologi bangsa indonesia. Dengan landasan tersebut, Direktorat Jenderal Pendidikan Tinggi mengembangkan esensi materi Pendidikan Pancasila yang meliputi:

1. Pengantar Perkuliahan Pendidikan Pancasila

2. Pancasila dalam Kajian Sejarah Bangsa Indonesia

3. Pancasila sebagai Dasar Negara

4. Pancasila sebagai Ideologi Negara

5. Pancasila sebagai Sistem Filsafat

6. Pancasila sebagai Sistem Etika

7. Pendekatan Pembelajaran Dasar Nilai Pengembangan Ilmu.

Pendekatan Pembelajaran yang direkomendasikan dalam Mata Kuliah Pendidikan Pancasila adalah pendekatan pembelajaran yang berpusat kepada mahasiswa (student ctered learning). Untuk memahami dan menghayati nilai-nilai Pancasila baik sebagai etika, filsafat negara, maupun ideologi bangsa secara scientific. Dengan harapan nilai-nilai Pancasila akan terinternalisasi sehingga menjadi guiding principles atau kaidah penuntun bagi mahasiswa dalam mengembangkan jiwa profesionalismenya sesai dengan jurusan/program studi masing-masing. Implikasi dari Pendidikan Pancasila tersebut agar 
mahasiswa dapat menjadi insan profesional yang berjiwa pancasila dalam kehidupan bermasyarakat dan bernegara. Selain itu, urgensi Pendidikan Pancasila adalah untuk membentengi dan menjawab tantangan perubahan-perubahan di masa akan datang.

Sebagai warga negara yang di bentuk dari sistem Pendidikan Ondonesia saat ini perlu mengetahui cita-cita yang harus dicapai dimasa yang akan datang sehingga dapat sebagai pijakan agar kehidupannya menjadi damai dan sejahtera. Dalam Undang-Undang Republik Indonesia Nomor 20 Tahun 2003, Pasal 3 menegaskan bahwa Pendidikan Nasional berfungsi mengembangkan dan membentuk watak serta perdaban bangsa yang bermatabat dalam rangka mencerdaskan kehidupan bangsa, bertujuan untuk berkembangnya potensi peserta didik agar menjadi manusia yang beriman dan bertakwa kepada tuhan yang maha esa, berakhlak mulia, sehat, berilmu, cakap, kreatif, mandiri, dan menjadi warga negara yang demokratis serta tanggung jawab.

Harapan tersebut memang tidak mudah untuk diwujudkan. Akan tetapi, pendidikan adalah alternatif baik dalam melakukan rekayasa sosial secara damai. Pendidikan adalah alternatif terbaik dalam melakukan sosial secara damai. Pendidikan Pancasila di perrguruan tinggi, perkenannya dengan memberikan kontribusi dalam pendalaman penghayatan dan penerapan nilai-nilai Pancasila kepada generasi baru banga. Atas dasar hal tersebut ,maka pemerintah menggunakan atau mengalokasikan 20\% dan APBN yang sebagian bersal dari pajak untuk membiayai pendidikan nasional

Setiap warga negara sesuai dengan kemampuan dan tingkatnya pendidikannya harus memiliki pengetahuan, pemahaman, penghayatan, penghargaan, komitmen, dan pengalaman Pancasila, lebih-lebih para mahasiwa yang notabene merupakan calon-calon pemegang tongkat estafet kepemimpinan bangsa harus memiliki penghayatan terhadap nilai-nilai pancasila karena akan menentukan eksistensi bangsa kedepan. Urgensi Pendidikan Pancasila di peguruan tinggi ini berlaku untuk semua jurusan/program studi, sebab nasib bangsa tidak hanya di tentukan oleh segelintir profesi yang di hasilkan oleh sekelompok jurusan/program studi saja, tetapi juga merupakan tanggung jawab semua bidang.

Urgensi Pendidikan Pancasila bagi suatu program studi, misalnya yang berkaitan dengan tugas menyusun/membentuk peraturan perundang-undangan. Orang yang bertugas untuk melaksanakan hal tersebut, harus mempunyai pengetahuan, pengertian, pemahaman, penghargaan, komitmen, penghayatan dan pola pengalaman yang lebih baik daripada warga negara yang lain karena merekalah yang akan menentukan merasap atau tidaknya 
nilai-nilai pancasila ke dalam peraturan perundang-undangan yang di susun/dibentuknya. Lulusan/output dari program studi energi di kemudian hari akan menentukan kebijakan tentang eksplorasi, eksploitasi, industrialisasi, dan distribusi energi dijalankan. Begitu pula dengan lulusan/output dari program studi perpajakan yang akan menjadi pengawai pajak maupun bekerja di bidang perpajakan dituntut memiliki kejujuran dan komitmen sehingga dapat memberikan kontribusi terhadap pelaksanaan kewajiban perpajakan tempat bekerja secara baik dan benar.

Demikian pula halnya bahwa keberadaan pendidikan pancasila merupakan suatu yang esensial bagi program studi di perguruan tinggi. Oleh karena itu, menjadi suatu kewajaran bahkan keharusan Pancasila di sebarluaskan secara masif, antara lain melalui mata kuliah pendidikan pancasila di perguruan tinggi. Dalam hal ini, Riyanto (2009: 4) menyatakan bahwa pendidikan pancasila di perguruan tinggi merupakan suatu keniscayaan karena mahasiswa sebagai agen perubahan dan intelektual muda yang di masa akan datang akan menjadi inti pembangunan dan pemegang estafet kepemimpinan bangsa dalam setiap tingkatan lembaga-lembaga negara, badan-badan negara, lembaga daerah, lembaga intfrastruktur politik, lembaga-lembaga bisnis, dan sebagainya.

Dengan demikian, pemahaman nilai-nilai pancasila di kalangan mahasiswa amat penting, tanpa membedakan pilihan profensinya di masa yang akan datang, baik yang berprofensi sebagai pengusaha/entrepreneur, pengawai swasta, pegawai pemerintah, dan sebagainya. Semua lapisan masyarakat memiliki peran amat menentukan terhadap eksistensi dan kejayaan bangsa di masa depan.

\section{B. PEMBAHASAN}

1) Internalisasi Nilai-Nilai Luhur Pancasila

\section{Pancasila dalam kajian sejarah Bangsa}

\section{a. Pancasila sebagai Identitas Bangsa Indonesia}

Identitas suatu bangsa disesuaikan dengan latarbelakang budaya masing-masing. Budaya dapat membentuk identitas suatu bangsa melalui proses inkulturasi dan akulturasi. Pancasila sebagai identitas bangsa Indonesia merupakan konsekuensi dari proses inkulturasi dan akulturasi tersebut. Inkulturasi adalah proses perpaduan berbagai elemen budaya dalam kehidupan masyarakat berkembang secara dinamis. 
Identitas Nasional Indonesia meliputi :

1. Bahasa Nasional adalah Bahasa Indonesia

2. Bendera Negara Sang Merah Putih

3. Lagu Kebangsaan adalah Indonesia Raya

4. Lambang Negara yaitu Pancasila

5. Semboyan negara Bhinekkha Tunggal Ika

6. Dasar falsafah bangsa Indonesia adalah Pancasila

7. Konstitusi negara adalah UUD1945

8. Bentuk negara kesatuan yang berkedaulatan rakyat

9. Konsepsi Wawasan Nusantara

10. Kebudayaan daerah yang menjadi kebudayaan nasional

Unsur-unsur pembentuk identitas bangsa adalah Suku, Agama, Kebudayaan, dan Bahasa.

\section{b. Pancasila sebagai Kepribadian Bangsa Indonesia}

Pancasila sebagai kepribadian bangsa artinya nilai-nilai ketuhanan, kemanusiaan, persatuan, kerakyatan, dan keadilan diwujudkan dalam sikap mental dan tingkahlaku serta perbuatan. Meskipun nilai ketuhanan, kemanusiaan, persatuan, kerakyatan, dan keadilan juga terdapat dalam ideologi bangsa-bangsa lain, tetapi bagi bangsa Indonesia kelima sila tersebut mencerminkan kepribadian bangsa karena diangkat dari nilai-nilai kehidupan masyarakat Indonesia sendiri dan dilaksanakan secara simultan. Pancasila sebagai kepribadian bangsa adalah perwujudan dari nilai-nilai budaya bangsa Indonesia sendiri yang diyakini kebaikan dan kebenarannya. Sebelum ditetapkannya Pancasila sebagai dasar yang sah, Indonesia memang sudah sejak dahulu menganut nilai-nilai budaya luhur yang telah tercipta di tengah-tengah masyarakat nenek moyang Indonesia. Pancasila digali dari budaya bangsa Indonesia sendiri yang ada, tumbuh, dan berkembang berabad-abad lamanya. Oleh karena itu, Pancasila adalah pribadi bangsa Indonesia itu sendiri yang hanya dimiliki oleh bangsa Indonesia sejak keberadaanya sebagai sebuah bangsa

\section{c. Pancasila sebagai Pandangan Hidup Bangsa Indonesia}

Sebagai pandangan hidup bangsa artinya nilai-nilai ketuhanan, kemanusiaan, persatuan, kerakyatan dan keadilan diyakini kebenarannya, kebaikannya, keindahannya dan kegunaanya oleh bangsa Indonesia yang dijadikan pedoman 
kehidupan bermasyarakat dan menimbulkan tekat yang kuat untuk mengamalkannya.

\section{d. Pancasila sebagai Jiwa Bangsa}

Von Savigny mengemukakan bahwa setiap bangsa mempunyai jiwanya masingmasing (volgeist)-Jiwa rakyat/jiwa bangsa. Pancasila sebagai jiwa bangsa lahir bersamaan dengan lahirnya bangsa Indonesia. Pancasila telah ada sejak dulu kala bersamaan dengan adanya bangsa Indonesia.

\section{e. Pancasila sebagai Perjanjian luhur}

Sebagai perjanjian luhur artinya nilai-nilai Pancasila sebagai jiwa bangsa dan kepribadian bangsa disepakati oleh para pendiri negara.

\section{2) Sumber Historis, Sosiologis, Yuridis dan Politis tentang Pancasila}

\section{Sumber Historis}

Presiden soekarno pernah mengatakan, "jangan sekali-kali meninggalkan sejarah", pernyataan tersebut dapat dimakinai bahwa sejarah mempunyai fungsi penting dalam membangun kehidupan bangsa dengan lebih bijaksana di masa depan. Hal tersebut sejalan dengan ungkapan seorang filsuf yunani yang bernama Cicero (106-43SM) yang mengungkapkan, "Historia vitae magistra", yang, bermakna, "sejarah memberikan kearifan". Pengertian lain dari istilah tersebut yang sudah menjadi pendapat umum (common-sense) adalah "sejarah merupakan guru kehidupan”. Implikasinya, pengyaan materi perkuliahan pancasila melalui pendekatan historis adalah amat penting dan tidak boleh dianggap remeh guna mewujudkan kejayaan bangasa di kemudian hari. Melalui pendekatan ini, mahasiswa diharapkan dapat mengambil pelajaran atau hikmah dari berbagai peristiwa sejarah, baik sejarah nasional maupun sejarah bangsa-bangsa lain. Dengan pendekatan historis adalah amat penting dan tidak boleh dianggap remeh guna mewujudkan kejayaan bangsa di kemudian hari. Melalui pendekatan ini, mahasiswa diharapkan dapat mengambil pelajaran atau hikmah dari berbagai peristiwa sejarah, baik sejarah nasional maupun sejarah bangsa-bangsa lain. Dengan pendekatan historis,anda diharapkan akan memperoleh inspirasi untuk berpartisipasi dalam pembangunan bangsa sesuai dengan program studi masing-masingg. Selain itu, anda juga dapat berperan serta secara aktif dan arif dalam berbagi kehidupan berbangsa dan bernegara, serta dapat berusaha menghindari perilaku yang bernuasa mengulangi kembali kesalahan sejarah. 
Dalam sejarah peristiwa nasional, banyak hikmah yang dapat di petik, misalnya mengapa bangsa Indonesia sebelm masa pergerakan nasional selalu mengalami kekalahan dari penjajah? Jawabannya antara lain karena perjuangan pada masa itu masi bersifat kedaerahan, kurang adanya persatuan, mudah pecah belah dan kalah dalam penguasaan IPTEKS termasuk dalam bidang persenjaatan. Hari ini berarti bahwa apanila integrasi bangsa lemah dan penguasaan IPTEKS lemah, maka Bangsa Indonesia dapat kembali. Implikasi dari pendekatan historis ini adalah meningkatkan motivasi keujangan bangsa dan meningkatkan motivasi belajar anda dalam menguasai IPTEKS sesuai dengan program studi masing-masing.

\section{Sumber Sosiologis}

Sosiologi dipahami sebagai ilmu tentang kehidupan antarmanusia. Di dalamnya mengkaji, antara lain latar belakang, susunan dan pola kehidupan sosial dari berbagai golongan dan kelompok masyarakat, disamping juga mengkaji masalahmasalah sosial, perubahan dan pembaharuan dalam masyarakat. Soekanto (1982:19) mengaskan bahwa dalam perspektif sosiologi, suatu masyarakat pada suatu waktu dan tempat memiliki nila-nilai yang tertentu. Melalui pendekatan sosiologis ini pula, anda diharapkan dapat mengkaji struktur sosial, proses sosial, termasuk perubahanperubahan sosial, dan masalah-masalah sosial yang patut disikapi secara arif dengan menggunakan standar nilai-nilai yang mengacu kepada nilai-nilai Pancasila.

Berbeda dengan bangsa-bangsa lain, Bangsa Indonesia mendasarkan pandangan hidupnya dalam bermasyarakat, berbangsa, dan bernegara pada suatu asas kultural yang dimiliki dan melekat pada bangsa, dan bernegara pada suatu asas kultural yang dimiliki dan melekat pada bangsa itu sendiri, nilai-nilai kenegaraan dan kemasyarakatan yang terkandung dalam sila-sila Pancasila bukan hanya hasil konseptual seseorang saja, melainkan juga hasil karya besar Bangsa Indonesia sendiri melalui proses refleksi filosofis para pendiri negara (Kaelan, 2000: 13). Bung Karno menegaskan bahwa nilai-nilai Pancasila digali dari bumi pertiwi Indonesia. Dengan kata lain, nilai-nilai Pancasila berasal dari kehidupan sosiologis masyarakat Indonesia. 


\section{Sumber Yuridis}

Pancasila sebagai dasar negara merupakan landasan dan sumber dalam membentuk menyelenggarakan negara hukum. Hal tersebut berarti pendekatan yuridis (hukum) merupakan salah satu pendekatan utama dalam pengembangan atau pengayaan materi mata kuliah pendidikan pancasila. Urgensi pendekatan yuridis ini adalah dalam rangka menegakkan undang-undang (law enforcement) yang merupakan salah satu kewajiban negara yang terpenting. Penegakan hukum ini hanya akan efektif, apabila di dukung oleh kesadran hukum ini hanya akan efektif, apabila didukung oleh kesadaran hukum warga negara terutam dari kalangan intelektualnya. Dengan demikian, pada gilirannya melalui pendekatan yuridis tersebut mahasiswa dapat berperan serta dalam mewujudkan negara hukum formal dan sekaligus negra hukum material sehingga dapat di wujudkan keteraturan sosial (social order) dan sekaligus terbangun suatu kondisi bagi terwujudnya pengingkatan kesejahteraan rakyat sebagaimana yang dicita-citakan oleh bangsa.

Kesadaran hukum tidak semata-mata mencakup Hukum Perdata dan Hukum Pidana, tetapi juga Hukum Tata Negara. Ketiganya membutuhkan sosialisasi yang seimbang di seluruh kalangan masyarakat, sehingga setiap warga negara mengetahui hak dan kewajibannya. Selama ini sebagian masyarakat masih lebih banyak menuntut haknya, namun melalaikan kewajibannya. Kesimbangan antara hak dan kewajiban akan melahirkan kehidupan yang harmonis sebgai bentuk tujuan negara mencapai masyarakat adil dan makmur.

\section{Sumber Politis}

Salah satu sumber pengayaan materi Pendidikan Pancasila adalah berasal dari fenomena kehidupan politik Bangsa Indonesia. Tujuannya agar anda mampu mendiagnosa dan mampu memformulasikan saran-saran tentang upaya atau usaha mewujudkan kehidupan politik yang ideal sesuai dengan nilai-nilai Pancasila. Pancasila dalam tataran tertentu merupakan ideologi politik, yaitu mengandung nilainilai yang menjadi kaidah penuntun dalam mewujudkan tata tertib sosial politik yang ideal. Melalui pendekatan politik ini, diharapkan mampu menafsirkan fenomena politik dalam rangka menemukan pedoman yang bersifat moral yang sesuai dengan nilai-nilai ideal yang menjadi kaidah penuntun atau pedoman dalam mengkaji konsepkonsep pokok dalam politik yang meliputi negara (state), kekuasaan (power), 
pengambilan keputusan (decision making), kebijakan (policy), dan pembagian (distribution) sumber daya negara, baik di pusat maupun di daerah. Melalui kajian tersebut, anda diharapkan lebih termotivasi berpartisipasi memberikan masukan kostruktif, baik kepada infrastruktur maupun suprastruktur politik.

\section{3) Pancasila dalam Butir-butir Sila-Sila Pancasila}

\section{Ketuhanan Yang Maha Esa}

a. Manusia Indonesia Percaya dan takwa kepada Tuhan Yang Maha Esa sesuai dengan agama dan kepercayaannya masing-masing menurut dasar kemanusian yang adil dan beradab.

b. Hormat menghormati dan bekerja sama antar para penganut kepercayaan yang berbeda-beda sehingga terbina kerukunan hidup.

c. Saling menghormati kebebasan menjalani ibadah sesuai dengan agama dan kepercayaannya.

d. Tidak memaksakan suatu agama dan kepercayaan kepada orang lain.

\section{Kemanusian Yang Adil dan Beradab}

a. Mengakui Persamaan derajat, persamaan hak, dan persamaan kewajiban asasi antar sesama manusia sesuai dengan harkat dan martabatnya sebagai makhluk Tuhan Yang Maha Esa.

b. Saling mencintai sesama manusia.

c. Mengembangkan sikap tenggang rasa.

d. Tidak semena-mena terhadap orang lain.

e. Menjunjung tinggi nilai kemanusiaan.

f. Gemar melakukan kegiatan kemanusiaan

g. Berani membela kebenaran dan keadilan

h. Bangsa Indonesia merasa dirinya sebagai bagian dari seluruh umat manusia. Oleh karena itu, dikembangkan sikap hormat menghormati dan bekerja sama dengan bangsa lain.

\section{Persatuan Indonesia}

a. Menempatkan persatuan, kesatuan, kepentingan, keselamatan bangsa dan bernegara di atas kepentingan pribadi atau golongan.

b. Rela berkorban untuk kepentingan bangsa dan negara.

c. Cinta tanah air dan bangsa. 
d. Bangga sebagai bangsa Indonesia dan bertanah air Indonesia.

e. Memajukan pergaulan demi persatuan dan kesatuan bangsa yang berbinekha tunggal ika

\section{Kerakyatan yang Dipimpin oleh Hikmat Kebijaksanaan dalam}

\section{Permusyawara-tan/Perwakilan.}

a. Sebagai warga negara dan warga masyarakat mempunyai kedudukan, hak, dan kewajiban yang sama dengan mengutamakan kepentingan negara dan masyarakat.

b. Tidak memaksakan kehendak kepada orang lain.

c. Mengutamakan musyawarah dalam mengambil keputusan untuk kepentingan bersama.

d. Musyawarah untuk mencapai mufakat diliputi oleh semangat kekeluargaan.

e. Dengan itikat yang baik dan rasa tanggung jawab menerima dan melaksanakan hasil keputusan musyawarah.

f. Musyawarah dilakukan dengan akal sehat dan sesuai dengan hati nurani yang luhur.

g. Keputusan yang diambil harus dapat dipertanggungjawabkan secara moral kepada Tuhan Yang Maha Esa, menjungjung tinggi harkat dan martabat manusia serta nilai-nilai kebeneran dan keadilan,dengan mengutamakan persatuan dan kesatuan demi kepentingan bersama.

\section{Keadilan Sosial bagi Seluruh Rakyat Indonesia}

a. Mengembangkan perbuatan yang luhur yang mencemirkan sikap dan suasana kekeluargaan dan kegotongroyongan.

b. Bersikap adil.

c. Menjaga keseimbangan antara hak dan kewajiban.

d. Menghormati hak-hak orang lain.

e. Suka memberi pertolongan kepada orang lain.

f. Menjauhi sikap pemerasan terhadap orang lain.

g. Tidak bersikap boros.

h. Tidak bergaya hidup mewah.

i. Tidak melakukan perbuatan yang merugikan kepentingan umum.

j. Suka berkerja keras.

k. Menghargai hasil karya orang lain. 
1. Bersama-sama berusaha mewujudkan kemajuan yang merata dan berkeadilan sosial.

\section{Penutup}

Urgensi Pendidikan Pancasila dapat memperkokoh jiwa kebangsaan mahasiswa sehingga menjadi dorongan pokok dan penunjuk jalan bagi calon pemegang estafet kepemimpinan bangsa di berbagai bidang dan tingkatan. Calon generasi kepemimpinan bangsa tidak mudah terpengaruh oleh paham-paham asing yang dapat mendorong untuk tidak dijalankannya nilai-nilai Pancasila. Pentingnya Pendidikan Pancasila diperguruan tinggi adalah untuk menjawab tantangan dunia dengan mempersiapkan warga negara yang menpunyai pengetahuan, pemahaman, penghargaan, penghayatan, komitmen dan pola pengamalan Pancasila. Untuk melahirkan lulusan yang menjadi kekuatan inti pembangunan, generasi muda bangsa dalam setiap tingkatan lembaga-lembaga negara, badan-badan negara, lembaga daerah, lembaga infrastruktur politik, dan lembaga lain menjunjung tinggi nilainilai luhur Pancasila.

\section{Daftar Pustaka}

Nurwardani, Paristiyanti dkk.2016.Pendidikan Pancasila Untuk Perguruan Tinggi, Cetakan I Kaelan. 2000. Pendidikan Pancasila. Yogyakarta. Paradigma

Abdulgani, Roeslan. 1979. Pengembangan Pancasila di Indonesia. Jakarta.Yayasan Idayu Riyanto, Astim. 2009. "Makalah Pendidikan Pancasila di Perguruan Tinggi: Tinjauan Yuridis".

Soekanto, Soerjono. 1982. Kesadaran Hukum dan Kepatuhan Hukum. Jakarta. CV. Rajawali.

\section{Peraturan-Peraturan}

Undang-Undang Republik Indonesia Nomor 12 tahun 2012 tentang Pendidikan Nasional Undang-Undang Republik Indonesia Nomor 20 Tahun 2003 tentang Sistem Pendidikan Nasional 


\section{CURRICULUM VITAE}

\section{DATA PRIBADI}

Nama Lengkap

: Warsito, SH.,S.Ag.,M.H.

Tempat dan tanggal lahir : Lampung, 2 Mei 1979

Alamat

: Puri Permata Blok B5 No. 25, Tangerang

Telepon/HP

: 081311370796

Email

: warsitosuranata79@gmail.com

Status Perkawinan

: Kawin

\section{PENDIDIKAN FORMAL}

$2009-2011$

S2 Universitas Borobudur, Jakarta

Magister Ilmu Hukum.

Konsentrasi Hukum Bisnis.

2003-2007

S1 Keagamaan.

STAB Maha Prajna, Jakarta

Jurusan Dharmacarya.

1998-2002

S1 Hukum, Universitas Bandar Lampung

Prodi Ilmu Hukum.

\section{PENGALAMAN KERJA}

1. Guru PKn di SMP dan SMA Sekolah Karya Iman, Lippo Cikarang, Bekasi Tahun 2005 2007

2. Dosen di STABN Sriwijaya, Tahun 2008 sampai sekarang

\section{PENGALAMAN PENELITIAN}

1. Upaya Peningkatan Kesadaran Hukum Mahasiswa STAB Negeri Sriwijaya TangerangBanten Tahun 2011.

2. Kajian Yuridis dan Sosiologis Tentang Pelanggaran Asusila Bagi Perumah-tangga dan Efek Yang Ditimbulkan Dalam Kelangsungan Hidup Berumah-tangga Tahun 2013.

3. Paradigma Kaum Puritan Dalam Pembentukan Keyakinan Beragama Pada Masyarakat Plural Tahun 2013.

4. Potensi Konflik Perilaku Keagamaan Dogmatis dan Fundamentalis Guru Agama Buddha di Jakarta Tahun 2014. 
5. Kajian Yuridis Tindak Pidana Mati dalam Pasal 10 KUHP dan Akibat Sosiologis Terpidana Sebelum Eksekusi serta Relevansinya dalam Doktrin Buddhisme Tahun 2015.

6. Peran Lembaga Hukum dalam Memberikan Perlindungan Hukum terhadap Korban Kekerasan dalam Rumah Tangga (Studi Kasus di Wilayah Hukum Kantor Hukum Anggoro-Fanani-Luhut di Jakarta)

7. Kajian Yuridis dan Sosiologis Mengenai Larangan Mengemis di Tempat Umum di Kota Tangerang (Studi Kasus pada Wilayah Hukum Kantor Dinas Sosial Kota Tangerang)

\section{KEGIATAN SEMINAR YANG PERNAH DIIKUTI}

1. Tahun 2015

a. Menjadi Observer The 12 th United Nation Nations Day of Vesak, Mahachulalongkornrajawidyalaya University, Thailand.

b. Menjadi Pemakalah tentang Semangat Kebangsaan (Nasionalisme) pada Seminar Nasional di Sekolah Tinggi Agama Buddha Negeri Raden Wijaya, Wonogiri Jawa Tengah.

2. Tahun 2016

Menjadi Observer 4th International ATBU Conference, Buddhist in Contemporary World : Challanges And Opportunities, Magelang Central Java. Indonesia

3. Tahun 2017

a. Menjadi Pemakalah pada Seminar tentang Revolusi Mental di STABN Sriwijaya Tangerang.

b. Mengikuti Seminar 6 Th Asean "Bridges-Dialoques Towards A Culture of Peace" Noble Laureate Lecture HE Jose Manuel Baroso, From National to Regional And Global Governance. Universitas Prasetya Mulya, BSD City Tangerang.

c. Mengikuti Seminar Bela Negara dan Wawasan Kebangsaan Oleh BKPBI dan Himahbudhi di STIE Kasih Bangsa, Jakarta.

d. Menjadi Narasumber tentang Wawasan Kebangsaan pada kegiatan Pengenal Kehidupan Kampus Bagi Mahasiswa Baru (PKKMB) di STABN Sriwijaya Tangerang dengan Tema "4 (Empat) Pilar Kebangsaan". 


\section{PENULISAN JURNAL}

1. Tahun 2016

a. Kontributor dalam Jurnal Pelita Dharma, STAB Negeri Sriwijaya Tangerang Banten dengan Topik "Menumbuhkan Kesadaran Hukum di Masyarakat dan Dunia Perguruan Tinggi" .

b. Kontributor dalam Jurnal Sati Sampajanna, STAB Negeri Sriwijaya Tangerang Banten dengan Topik "Tindak Pidana Mati dalam Kajian Hukum dan Sosial serta relevansinya dengan ajaran Buddha" 